Article

\title{
The importance of music education in the development and performance of executive functions
}

\section{Carlos Domínguez ${ }^{*}$}

\author{
${ }^{1}$ Programa de Maestría y Doctorado en Música. Universidad Nacional Autónoma de México. Calle Xicoténcatl \\ 126, Del Carmen, Coyoacán, 04100 Ciudad de México, CDMX. \\ *Correspondence: d.incidental@gmail.com Tel: +52 5540853828
}

\begin{abstract}
Abstact
In recent years, music education in Ibero-America has been losing ground within the school environment in favor of the development of curricular systems that benefit academic results in standardized tests. Despite this, several studies in the field of cognitive neurosciences have found evidence of great relevance and in which it can be observed how music education can favor cognitive development and performance in practically all stages of human development, with important results in language tasks, attention, and executive functions such as planning, inhibition, cognitive flexibility and working memory.
\end{abstract}

Keywords: Executive functions, music education, cognitive development, planning, inhibition, decision making, working memory.

\section{Introduction}

In the course of the last two decades, science has been delivering significant results regarding the positive impact of music education both in behavior and in the development of cognitive skills (attention, language, reasoning, logical, critical and mathematical thinking, planning, inhibition of emotions and working memory, among others) of human beings in practically all stages of development. Despite this, in Mexico and much of Latin America, music education, although not completely out of the curriculum, has gradually been distorted in favor of a complete arts education (dance, visual arts, theater), in which, teachers, in certain cases, before the given requirements of the educational institutions, end up opting for one or another artistic activity, approaching music sporadically and almost superficially. This, 
Music education and executive functions

without counting all those cases in which the music or arts class ends up in the hands of the teachers in charge of the areas of physical activity and sports or religion.

Numerous music educators and researchers have highlighted the importance of music education in the critical and reflective formation of school-age children, facilitating the development and enrichment of the mind and personality (Gamboa, 2016), despite this, the lack of information about the contributions of science regarding the benefits of music education in the neurocognitive and behavioral development of human beings, could become critical when addressing projects focused on formal music education processes.

Therefore, in order to begin to understand and delimit the role of music education in the neurocognitive development of human beings, it is important to begin to understand what some of these mental processes are and how they work, among them, the executive functions.

\section{Executive functions}

One of the qualities that separates human beings from the rest of the animal species is the ability to control their instincts or innate behaviors through the inhibition of their emotions with respect to their plans, goals and rules (Grange and Houghton, 2014). This set of mental tools that make personal independence and emotional self-regulation possible (Barkley, 2012; Zuk, Benjamin, Kenyon, \& Gaab, 2014), are commonly referred to as executive functions (EF's). And although EF's do not have a universally agreed definition, as they have with certain constructs and principles of learning (Kalbfleish, 2017), they can, roughly speaking, be understood as a series of neurobiological processes (García-Molina et al., 2009) or multidimensional cognitive constructs that enable the gain of strategic control over mental processes (Bowmer et al., 2018) related to tasks of planning, reasoning, decision making, cognitive flexibility, working memory (Jaschke et al., 2018) and inhibition, all of them, indispensable tools in the daily life of human beings (Domínguez et al., 2020). Another mental ability that is strongly related to the concept of EF's, is the construct of metacognition (Lazarus and Ostrosky-Solis, 2012) and that is, in short, the ability of human beings to be aware of information processing by constantly monitoring to the cognitive processes required for one or different tasks (Bowmer et al., 2018). In other words, the human ability to form and integrate complex ideas about oneself or another people (Hochheiser et al., 2019).

The development of EF's is related to the maturation of certain areas of the frontal lobes (Johnson et al., 2009), particularly the prefrontal cortex (PFC), a structure strongly linked to complex behaviors and characterized by rapid growth during early childhood (Bowmer et al., 2018). In a study conducted by Tillman et al. (2015) in children between five and seven years of age with Attention Deficit Hyperactivity Disorder (ADHD), it was observed that the development of the EF's occurs in a hierarchical manner, due to a possible correlation of 
Music education and executive functions

processes, which would start with the ability to inhibit behaviors from six months, to planning and decision making whose development usually lengthen until well into adulthood.

In several studies of EF's, it has been possible to observe the correlation of processes mentioned by Tillman et al. (2015), as in the case of Brocki et al. (2015) who, in studies in children aged eight to 12 years, found a correlation between better results in inhibition and attention tasks, with better performance in working memory tasks four years later. Similarly, Moffitt and Gottschalk, (2011) in a longitudinal study in which they evaluated the performance of children between the ages of three and 11 in EF's tasks, observed that lower performances in inhibition tasks were strongly related to lower income, deteriorated health status, violent behaviors and high crime rates up to 30 years later. Now, while these data are interesting, making such predictions based on early judgments could lead to unstable constructs (Mulder, Verhagen, Van der Ven, Slot, \& Leseman, 2017), based on EF's studies in children under three years is relatively scarce (Garon, Smith, \& Bryson, 2014).

Inhibitory control or inhibition is one of the executive functions of the brain that focuses on the intentional and voluntary control of behaviors, that is, the ability to modulate instinctive responses (Hennessy et al., 2019), preventing the interference of little or no important information before responses already underway (Domínguez, 2020), suppressing information that, despite the ability to bring short-term pleasure, is not relevant to the task in progress or to be performed (Rubiales et al., 2013). In children, the development of inhibitory control is a particularly difficult skill to achieve, despite this, it has been seen that, it is from six months of age when they begin to give the first signs of inhibitory control (Bowmer et al., 2018). Although it is from the age of two and a half years that they are ready to inhibit incompatible objects no matter how predominant they are, a task that will reach up to $90 \%$ accuracy from the age of three years (Geradi-Caulton, 2000).

Planning is the ability to generate efficient and useful responses in a wide range of situations in order to satisfy one's own needs or those of the environment based on stimuli, knowledge and experiences (Kaller et al., 2011). And although planning is a mental ability of long development, it has been seen that it is from the age of four when children begin to show signs of skill in situations or tasks that involve planning solutions to certain types of problems (Welsh et al., 1991), as is often the case during playtime, despite this, their strategies are not usually entirely effective, since it is between seven and 11 years of age when strategic behaviors and reasoning skills, necessary for effective planning, become more organized (Anderson, Anderson and Garth, 2001).

Working memory is a useful neural tool in the processes of storage and temporal manipulation of information in the brain and is extremely useful in the processes of language comprehension, reasoning, learning and music processing (Van de Cavey and Hartsuiker, 2016). Although there are different positions regarding working memory, some researchers argue that the difference between working memory and short-term memory lies in the fact 
Music education and executive functions

that short-term memory is a passive storage device of information, unlike working memory that allows the manipulation, comparison and contrast of information (Baddeley, 2012) coming from each of the sensory inputs (Etchepareborda and Abad-Mas, 2005) in order to create structural representations (Van de Cavey and Hartsuiker, 2016). For Baddeley (1983), working memory is active, limited and susceptible to interruptions, but it is this susceptibility that tinges it with the flexibility that characterizes it, since it is only because of it that human beings harbor the ability to perceive new information constantly.

There are different reasons why EF's have been considered important tools in practically all aspects of life, one of them is due to the close relationship they have with academic performance and achievement in both children and adults (Barkley, 2012; Zuk et al., 2014), benefiting the disposition to learn (Bowmer et al., 2018; Diamond, 2013; Mulder et al., 2017). And another, to the possible relationship that seems to exist between the performance of EF's at early ages and higher probabilities of economic and professional success during adulthood (Hennessy et al., 2019).

Thus, it can be said that executive functions are mental tools or neurobiological processes that enable the development of vital tasks in the daily life of human beings, favoring the readiness to learn.

\section{Music education in Ibero-America}

Music class is an area that, in general, is contemplated within the curricula of compulsory education in most Western countries (Carrigo aguilera, Viladot Vallverdú, Pérez-Moreno, 2017). Despite this, in many educational systems, at least at the Ibero-American level, music education is in a moment of crisis, since, curricular models in some countries have given priority to certain subjects to the detriment of others that, in some way, are considered less important or secondary; such is the case of music education (Peñalba, 2017). For example, although during the 1990s, in Spain, the teaching of music was generalized in the compulsory educational stages, with the appearance of the Organic Law For The Improvement Of Educational Quality (LOMCE, Jefatura del Estado, 2013), music education was established as an optional area in the curriculum of elementary and secondary education, which introduces the possibility that students conclude their compulsory education without having experienced any kind of musical practice in a formal way (Carrillo Aguilera et al., 2017). This, in part, could be a consequence of the decadence of the educational institution (Alvarado, 2018) because of a system founded on neoliberal pragmatism (Schipper, 2014). Reason why states, in economics' crisis times, firsthand, favor the financial system before social interests (Davies, 2014). Despite this, music education could be losing strength within schools due to the fact that, educational systems, favor or defend curricular models focused on improving academic results based on standardized tests (Aróstegui, 2016), as may well be 
Music education and executive functions

the case of the PISA (Programme for International Student Assessment) tests, which evaluates three areas of knowledge: Science, Reading and Mathematics (OECD, 2020); TIMMS (Trend in International Mathematics and Science Study) which evaluates mathematics and science; PIRLS (Progress in International Reading Literacy Study) which evaluates reading comprehension (TIMMS \& PIRLS, 2020); or the SABER tests of the Colombian Institute for the Promotion of Higher Education (ICFES), which evaluate year after year the performance of students in primary and secondary school in areas of language, mathematics, natural sciences and citizenship competencies (Mineducación, 2020). All this undoubtedly has a negative impact on the allocation of resources to music education.

\section{The role of music education in the performance of executive functions}

Music is probably one of the tools that most favors the neurocognitive development of human beings, with visible evidence both at the cortical and behavioral levels. But, although the term music can be understood as "listening to music", on this occasion, I will use the word music in strict reference to music training, that is, to the formal study of music. However, it is worth mentioning that Jascheke et al, (2018a), reports that, in enriched environments in which 176 children listened to music at home, during playtime or in concert halls, and to whom the verbal intelligence section of the Wechsler Intelligence Scale (WISC III) and some other executive function tasks such as planning (Tower of London) were applied, working memory (Matrix backward span), inhibition (Go/no-Go task) and short-term memory tasks (Klingberg Matrix forward span), it was observed that none of the applied analyses yielded significant results between exposure to musically enriched environments and executive function or short-term memory tasks. Therefore, listening to music is not related to improvements in the performance of executive function tasks. However, it has been shown that listening to music could be related to improvements in the performance of verbal intelligence skills, as well as changes in the functional and structural connectivity of the brain of untimely babies, particularly in the posterior cingulate cortex (Haslbeck et al., 2020).

In several studies in which the effect of music training on the performance of EF's in schoolaged children has been studied, it has been found that, in all cases, the groups of participants who received music lessons showed better performance in tasks of inhibitory control, cognitive flexibility, working memory and planning. For example, in a study conducted by Guo et al. (2018) in children aged six to eight years to whom a 12-session music training was applied over six weeks, it was observed that, compared to a control group, all children who were part of the music training, achieved better scores in working memory tasks. Similarly, it has been shown that systematic extracurricular musical training is associated with changes in cognitive control networks in the brain, even in the absence of changes in behavioral performance (Sachs et al., 2017). Similarly, Shen et al., (2019) observed that, after a 12-week music training, in which, children in the experimental group received classes in music theory, 
Music education and executive functions

singing, dancing and some role-playing, they performed better on tests of inhibitory control, working memory and cognitive flexibility compared to the control group that maintained their academic activities without any changes. And although they noted the important role of music training in the performance of EF's, they managed to observe that, in a new evaluation of EF's 12 weeks after the end of the intervention, the results persisted. Therefore, the effects of integrated musical training on the performance of certain executive processes could have a long-term permanence. Similarly, a positive influence of long-term music education on certain cognitive skills such as inhibition and planning has been seen (Jaschke et al., 2018b).

And while there are opposing views among some researchers and music educators regarding the potential benefits of music training that usually occurs within a musical grouping, either band or symphony orchestra, Fassano et al., (2019) in a study conducted on 113 children aged eight to 10 years in Italy, observed that, after 3 months of orchestral music training, consisting of two hours per week and a final concert, in which, all children were administered with tests and questionnaires of inhibitory control and hyperactivity at the beginning and at the end, the 55 children in the sample group, at the end of the experiment, had a significant improvement in inhibitory control tasks compared to the control group. Therefore, an intense or a brief orchestral musical training, is more than enough to facilitate the development of inhibitory control (Fassano et al., 2019). Similarly, learning to play a musical instrument over several weeks has been found to be beneficial in the development of working memory in children (Guo et al., 2018). Similarly, learning to play an instrument at an early age, could predict academic performance and intelligence quotient (IQ) in early adulthood (Miendlarzewska and Trost, 2014). And while, various research has demonstrated the benefits of studying music on the development of EF's, many of these have been seen particularly in childhood (Criscuolo et al., 2019). In a study carried out in the United Kingdom in three- and four-years old's children, in which the effects of weekly music training were studied, Bowmer et al., (2018), observed that the children who were part of the sample group and who received eight weekly music lessons by specialist teachers in the musical area, improved their mental abilities in terms of inhibition and planning tasks, with respect to the two control groups that remained with their usual play activities in the nursery.

Jaschke et al., (2018b), in a longitudinal study of two and a half years in which the performance of inhibitory control, planning and verbal intelligence skills was evaluated in 147 elementary school children randomly divided into four groups, two musical, one visual arts and a control group, observed that there was a significant increase in the scores of children belonging to the musical groups compared to the other two groups. This not only supports the existing theoretical foundation between the benefits of studying music and performance in executive function tasks, but, in a certain way, could favor academic performance. This, based on the fact that, mediation analyses between executive functions and verbal IQ as mediators of academic performance have shown a possible distant transfer effect from executive subfunction to academic performance scores (Jaschke et al., 2018b). 
Music education and executive functions

\section{Conclusions}

Cognitive neurosciences, in the course of the last decades, have made great findings regarding to the manifold benefits that an early music education can induce in the behavioral and cognitive development of human beings, significantly improving the performance of all those processes related to executive function tasks (inhibitory control, planning, cognitive flexibility and working memory) and some other cognitive processes related to language, for example, reading comprehension.

Now, although music education is not going through its best moment in Ibero-America, as it has been relegated in favor of areas included in certain standardized evaluation models, this is not because music education, especially in the basic education grades, is not relevant within the educational field, but because of the lack of information that exists both in the entities in charge of the curricular regulation of the educational systems and in the educational institutions that favor mass storage of information over understanding and analysis of the information that is stored, and, in many cases, to the music educators themselves who, for one reason or another, are unaware of the relevance of their role within the school environment and the neurocognitive development of human beings. Based on various studies and research, it has been corroborated that music favors performance in areas such as reading comprehension, the acquisition of a second language, logical and critical thinking, and decision making. In conclusion, if early performance in executive function tasks could be related to higher probabilities of future success, and music education favors the development of EF's, musical training, would not only favor the behavioral and cognitive development of children, but could maintain a relationship with social and personal success during adulthood.

Funding: This work did not receive financial support from any public or private institution.

\section{Conflicts of interest: None.}

\section{References}

Alvarado, R., (2018). La crisis de la educación musical como consecuencia de la decadencia de la institución educativa. Revista Educación, vol. 42 núm. 2, 2018. Universidad de Costa Rica. DOI: https://doi.org/10.15517/revedu.v42i2.29055

Anderson, P., Anderson, V., \& Garth, J. (2001). Assessment and Development of Organizational Ability: The Rey Complex Figure Organizational Strategy Score (RCF-OSS)*. In The Clinical Neuropsychologist (Vol. 15, Issue 1, pp. 81-94). https://doi.org/10.1076/clin.15.1.81.1905

Baddeley, A. (2012). Working memory: theories, models, and controversies. Annual Review of Psychology, 63, 1-29. https://doi.org/10.1146/annurev-psych-120710-100422 


\section{Music education and executive functions}

Barkley, R. A. (2012). Executive Functions: What They Are, How They Work, and Why They Evolved. Guilford Press. https://books.google.com/books/about/Executive_Functions.html?hl=\&id=7c39F6qD38IC

Bowmer, A., Mason, K., Knight, J., \& Welch, G. (2018). Investigating the Impact of a Musical Intervention on Preschool Children's Executive Function. Frontiers in Psychology, 9, 2389. https://doi.org/10.3389/fpsyg.2018.02389

Carrillo Aguilera, C.; Viladot Vallverdú, L.; Pérez-Moreno, J. (2017). Impacto en la educación musical: una revisión de la literatura científica, en Revista Electrónica Complutense de Investigación en Educación Musical, 14, 61-74.

Criscuolo, A., Bonetti, L., Särkämö, T., Kliuchko, M., \& Brattico, E. (2019). On the Association Between Musical Training, Intelligence and Executive Functions in Adulthood. Frontiers in psychology, 10, 1704. https://doi.org/10.3389/fpsyg.2019.01704

Davies, W. (2014). Neoliberalism: A Bibliographic Review. Theory, Culture \& Society, 0(0), 1-9. doi: https://doi.org/10.1177/0263276414546383

Diamond, A. (2013). Want to Optimize Executive Functions and Academic Outcomes? Simple, Just Nourish the Human Spirit. In Minnesota Symposia on Child Psychology (pp. 203-230).

Etchepareborda, M. C., \& Abad-Mas, L. (2005). Memoria de trabajo en los procesos básicos del aprendizaje. Revista de Neurología, 40(1), 79-83. http://www.academia.edu/download/36801310/Memoria_3.pdf

Fasano, M. C., Semeraro, C., Cassibba, R., Kringelbach, M. L., Monacis, L., de Palo, V., Vuust, P., \& Brattico, E. (2019). Short-Term Orchestral Music Training Modulates Hyperactivity and Inhibitory Control in School-Age Children: A Longitudinal Behavioural Study. Frontiers in psychology, 10, 750. https://doi.org/10.3389/fpsyg.2019.00750

Gamboa Suárez, A. A., (2016). Educación musical: escenario para la formación del sujeto o un pariente pobre de los currículos escolares. Saber, ciencia y libertad. Pp. 2015-224. DOI: https://doi.org/10.18041/23823240/saber.2017v12n1.719

Garon, N., Smith, I. M., \& Bryson, S. E. (2014). A novel executive function battery for preschoolers: Sensitivity to age differences. Child Neuropsychology: A Journal on Normal and Abnormal Development in Childhood and Adolescence, 20(6), 713-736. https://doi.org/10.1080/09297049.2013.857650

Guo, X., Ohsawa, C., Suzuki, A., \& Sekiyama, K. (2018). Improved Digit Span in Children after a 6-Week Intervention of Playing a Musical Instrument: An Exploratory Randomized Controlled Trial. Frontiers in psychology, 8, 2303. https://doi.org/10.3389/fpsyg.2017.02303

Haslbeck, F. B., Jakab, A., Held, U., Bassler, D., Bucher, H. U., \& Hagmann, C. (2020). Creative music therapy to promote brain function and brain structure in preterm infants: A randomized controlled pilot study. NeuroImage. Clinical, 25, 102171. https://doi.org/10.1016/j.nicl.2020.102171

Hennessy, S. L., Sachs, M. E., Ilari, B., \& Habibi, A. (2019). Effects of Music Training on Inhibitory Control and Associated Neural Networks in School-Aged Children: A Longitudinal Study. Frontiers in Neuroscience, 13, 1080. https://doi.org/10.3389/fnins.2019.01080

Hochheiser, J., Lundin, N. B., \& Lysaker, P. H. (2019). The Independent Relationships of Metacognition, Mindfulness, and Cognitive Insight to Self-Compassion in Schizophrenia. The Journal of Nervous and Mental Disease. https://doi.org/10.1097/NMD.0000000000001065

Kaller, C. P., Rahm, B., Spreer, J., Weiller, C., \& Unterrainer, J. M. (2011). Dissociable Contributions of Left and Right Dorsolateral Prefrontal Cortex in Planning. In Cerebral Cortex (Vol. 21, Issue 2, pp. 307-317). https://doi.org/10.1093/cercor/bhq096

Miendlarzewska, E. A., \& Trost, W. J. (2014). How musical training affects cognitive development: rhythm, reward and other modulating variables. Frontiers in neuroscience, 7, 279. https://doi.org/10.3389/fnins.2013.00279

Mineducación, (2020). Pruebas saber. Recuperado el 14 de enero de 2021 de, https://n9.cl/9uzc3 


\section{Music education and executive functions}

Moffitt, R., \& Gottschalk, P. (2011). Trends in the Transitory Variance of Male Earnings in the U.S., 1970-2004. https://doi.org/10.3386/w16833

Mulder, H., Verhagen, J., Van der Ven, S. H. G., Slot, P. L., \& Leseman, P. P. M. (2017). Early Executive Function at Age Two Predicts Emergent Mathematics and Literacy at Age Five. Frontiers in Psychology, 8, 1706. https://doi.org/10.3389/fpsyg.2017.01706

OCDE, (2020). Programa Internacional de Evaluación de los Alumnos (PISA). Recuperado el 14 de enero de 2021 de, https://n9.cl/xaxre

Peñalba, A., (2017). La defensa de la educación musical desde las neurociencias. Rev. Electrón. Complut. Inves. Educ. music. 14, 2017:109-127. http://dx.doi.org/10.5209/RECIEM.54814

Rubiales, J., Bakker, L., \& Urquijo, S. (2013). Estudio comparativo del control inhibitorio y la flexibilidad cognitiva en niños con TDAH. Cuadernos de Neuropsicologia-Panamerican Journal of Neuropsychology, 7(1), 50-69. https://www.aacademica.org/sebastian.urquijo/34

Sachs, M., Kaplan, J., Der Sarkissian, A., \& Habibi, A. (2017). Increased engagement of the cognitive control network associated with music training in children during an fMRI Stroop task. PloS one, 12(10), e0187254. https://doi.org/10.1371/journal.pone.0187254

Schipper, S. (2014). The financial crisis and the hegemony of urban neoliberalism: Lessons from Frankfurt am Main. International journal of urban and regional research, 38(1), 236-255. doi: https://doi.org/10.1111/1468-2427.12099

Jaschke, A. C., Honing, H., \& Scherder, E. (2018A). Exposure to a musically-enriched environment; Its relationship with executive functions, short-term memory and verbal IQ in primary school children. PloS one, 13(11), e0207265. https://doi.org/10.1371/journal.pone.0207265

Jaschke, A. C., Honing, H., \& Scherder, E. (2018B). Longitudinal Analysis of Music Education on Executive Functions in Primary School Children. Frontiers in neuroscience, 12, 103. https://doi.org/10.3389/fnins.2018.00103

Jefatura del Estado (2013). Ley Orgánica 8/2013 de 9 de diciembre, para la mejora de la calidad educativa (LOMCE). Boletín Oficial del Estado (10 de diciembre).

Johnson, S. B., Blum R. W., and Giedd, J. N. (2009). Adolescent maturity and the brain: the promise and pitfalls of neuroscience research in adolescent health policy. J. Adolesc. Health? 45, 216-221. Doi:10.1016/j.jadohealth.2009.05.016

Kalbfleisch, L. (2017). Neurodevelopment of the Executive Functions. In Executive Functions in Health and Disease (pp. 143-168). https://doi.org/10.1016/b978-0-12-803676-1.00007-6

Lázaro, J. C. F., \& Ostrosky-Solís, F. (2012). Desarrollo neuropsicológico de lóbulos frontales y funciones ejecutivas. Editorial El Manual Moderno. https://play.google.com/store/books/details?id=xNPHCQAAQBAJ

TIMSS \& PIRLS International Study Center (2020). Recuperado el 14 de enero de 2021 de, https://timssandpirls.bc.edu/

Tillmann, B. (2012). Music and language perception: expectations, structural integration, and cognitive sequencing. Topics in Cognitive Science, 4(4), 568-584. https://doi.org/10.1111/j.1756-8765.2012.01209.x

Van de Cavey, J., \& Hartsuiker, R. J. (2016). Is there a domain-general cognitive structuring system? Evidence from structural priming across music, math, action descriptions, and language. Cognition, 146, 172-184. https://doi.org/10.1016/j.cognition.2015.09.013

Welsh, M. C., Pennington, B. F., \& Groisser, D. B. (1991). A normative-developmental study of executive function: A window on prefrontal function in children. In Developmental Neuropsychology (Vol. 7, Issue 2, pp. 131-149). https://doi.org/10.1080/87565649109540483

Zuk, J., Benjamin, C., Kenyon, A., \& Gaab, N. (2014). Behavioral and neural correlates of executive functioning in musicians and non-musicians. PloS One, 9(6), e99868. https://doi.org/10.1371/journal.pone.0099868 